\title{
Models of Geometric Representation and Analysis of Just Value of Property in 2D and 3D Formats
}

\author{
Shokhmansur Shokhazamiy ${ }^{1}$, Rustam Abduraupov, ${ }^{2 *}$ MirganiAkbarov $^{3}$ \\ ${ }^{1}$ Tashkent Financial Institute, Tashkent, Uzbekistan \\ ${ }^{2}$ Tashkent State University of Economics, Tashkent, Uzbekistan \\ ${ }^{3}$ Tashkent Financial Institute, Tashkent, Uzbekistan \\ *rustamabduraupov@gmail.com
}

\begin{abstract}
We have devoted the paper to determining the just value of a company according to the geometric model, which uses the appropriate quantitative values with respect to the real (intrinsic) fundamental (internal) value of a company and the objective price of its shares. Furthermore, the papers provides with the appropriate conclusions, theoretical suggestions and practical recommendations, which are useful for the investors and managers in making operating (current, quick) financial decisions.
\end{abstract}

Keywords: Just value, geometric model, fundamental value, objective price of a share, complex number

\section{Introduction}

The activity of modern public companies cannot be separated from cost and price criteria, as they are used in assessing the effectiveness and making fair management decisions. The fairness of managerial decisions should be based on the just value ${ }^{1}$ of the company, which is formed from the real (intrinsic) fundamental (internal) value ${ }^{2}$ and an objective price of its shares ${ }^{3}$ in the open stock market. The reason for that is the desire for continuous growth of stock indexes (prices) and market capitalization is superior over the importance of productivity growth and real effectiveness of companies. In other words, the principle of absolutization the profitability in companies ${ }^{4}$ led to unnecessary inflation of the price of capital in the securities market (SM), inflation of demand for derivatives, financialization of capital and migration to the financial and credit sector, and, ultimately, to a strong separation of financial capital from actual reproduction process, thus the formation of "bubbles" in real assets. ${ }^{5}$ Although the creation of real wealth is only possible in the real economy - the production and reproduction of real goods, and financial and credit sector is designed to provide this sector with financial resources.

In this issue the market share price is formed on SM under the influence of many factors (pricing, including random, opportunistic), whereby objectivity essential characteristics of the stock price is reduced. The external (independent) assessment of a company should be carried out by the experts (assessors) considering value-creational factors. It should include methodological and subjective nature, by virtue of which the estimation of the essential characteristics of the company's value is reduced. Therefore, it is advisable to determine a just value of the company (JVC) as a function of the equivalent of arguments - the fundamental value of the company (FVC), which is formed on the appraisal market (AM) and objective price

\footnotetext{
${ }^{1}$ Comparing with the "fair value", which is very popular in the world on finance, "just value" has another treatment. Just value is the value, which corresponds with the equivalent meanings of real (intrinsic) internal (fundamental) value of a company and objective price of its shares, which are accessible freely in the open stock market. These meanings are just because of their correlation in the acceptable area of equivalency. The correlation of the real internal value and the objective price of a share may be expressed by the formalized statistical and geometrical models. Note: in case of having difficulties in determining the objective prices of shares in the open market, we can take the most reliable (the most appropriate to the current conjuncture of the property market) value, which may be chosen on the basis of three generally accepted assessment approaches of a company's value.

${ }^{2}$ Kudina (2010) devoted her research to the concept of fundamental value. In general the fundamental value is created in production process and not only reflects interests of investors, but also promotes the creation of the real wealth and the prosperity of the society.

${ }^{3}$ Objective price of a company's shares is the price of the shares in the open stock market that does not prompt any doubts to anyone. It is formed by objective demand and supply with rather continuous and stable indices.

${ }^{4}$ The race for capitalization at any costs.

${ }^{5}$ There are credit, currency, insurance and stock "bubbles" (Shokhazamiy, 2009, 2010b)
} 
of its shares (OPCS), which is formed on the development of securities market. ${ }^{6}$ This kind of formulation is related to the identification, delineation and analysis of value-creating and pricing factors in the formation of JVC in market conditions.

\section{Geometric model}

The analysis and determination of JVC be accomplished using a method based on the geometric model (shown in Figure 1) 7 , which applies the appropriate quantity of (data) with respect to the FVC and OPCS with a depth of at least 5 years. As it can be seen in Figure 1, with the help of this model in 3D we can systematically analyze in conjunction the price, the value and number of securities traded in the securities market and assessed in AM. Along with the model shown in Figure 1, it can also be used as 2-dimensional geometric model (Figure 2) ${ }^{8}$. A 2D-format estimate the fair value of the securities on the basis of indicators expressed as a complex number ${ }^{9}$ :

$$
Z_{C}=r+j m^{10}
$$

Based on the analysis of vectors and angles relative to the $\mathrm{X}$ axis in the model, we can get answers to the questions such as: "What is the reality degree of value of a security as a real asset, characterized by a fundamental value, formed in the appraisal market?", "What is the objectivity degree of a price of the securities which are bought and sold in the open stock market depending on its free environment?". The first question is related to the methodology of experts' assessment of the fundamental (real, intrinsic) value of the company (securities) and art appraiser, whereas the second one is associated with a professional art and objectivity of a broker (trader) and the development of the stock market.

\section{Figure 1: 3-D Geometric Economic Model of Systemic Analysis}

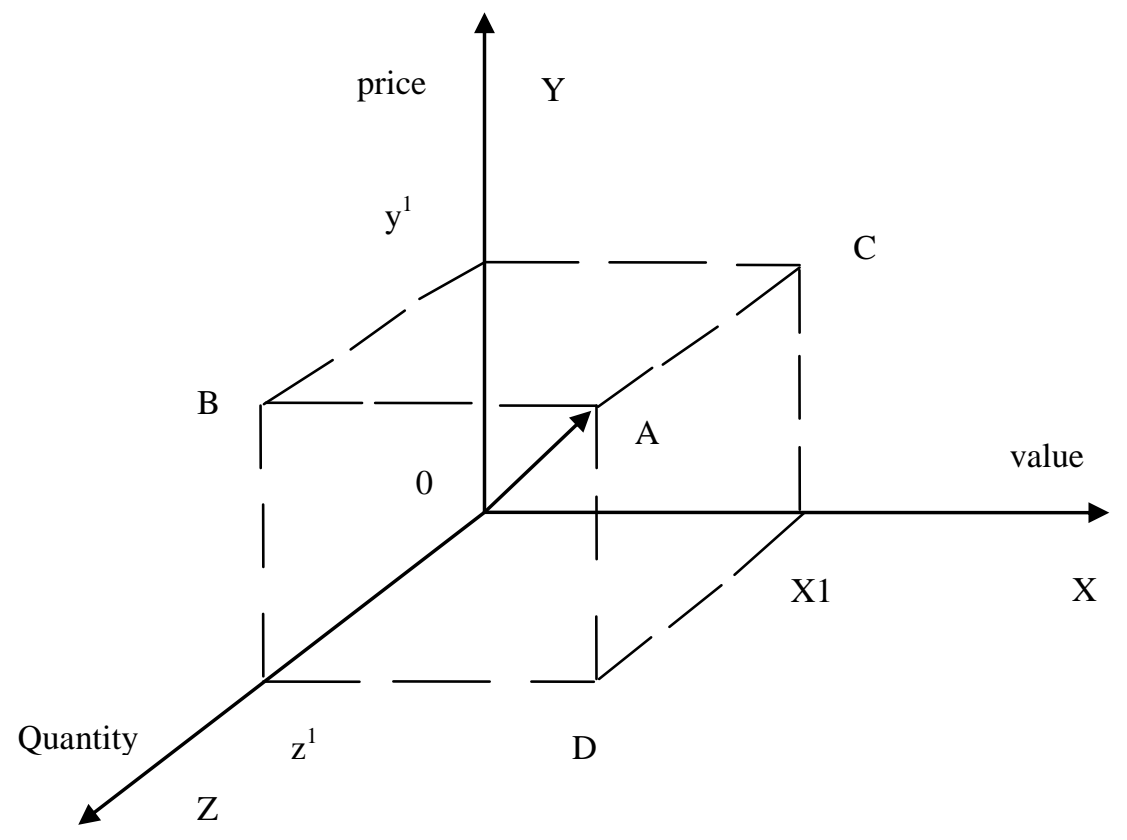

\footnotetext{
${ }^{6}$ The AM and SM are linked by a regulative element and called as Market of Forming Value and Price (MFVP). Note that these markets are equivalent in terms of their correlation $(0,91)$ (Shokhazamiy, 2012b, 2013b).

${ }^{7}$ The model is first presented by Shokhazamiy (2012a, 2012b, 2012c, 2013a).

${ }^{8}$ A number of shares is also consideredin the following model (Shokhazamiy, 2010a, 2012b, 2012c, 2013a).

${ }^{9}$ where $\mathrm{r}$ - the real part; $\mathrm{jm}$ - the imaginary part; $\mathrm{j}$ - a symbol that defines $\mathrm{m}$ belonging to the speculative market category. And the + symbol in the formula does not mean the addition operation, the real part of the formula characterizes real (fundamental) value, but the imaginary part - the virtual value (price), which is formed in the development SM.

${ }^{10}$ The model (Figure 2) is used in finance-metrical, secure-metrical and market-metrical analysis (Shokhazamiy, 2010a, 2012b, 2012c, 2013a).
} 
Figure 2: The Model of Geometric Interpretation of $\mathrm{Z}_{\mathrm{C}}$ Indicator

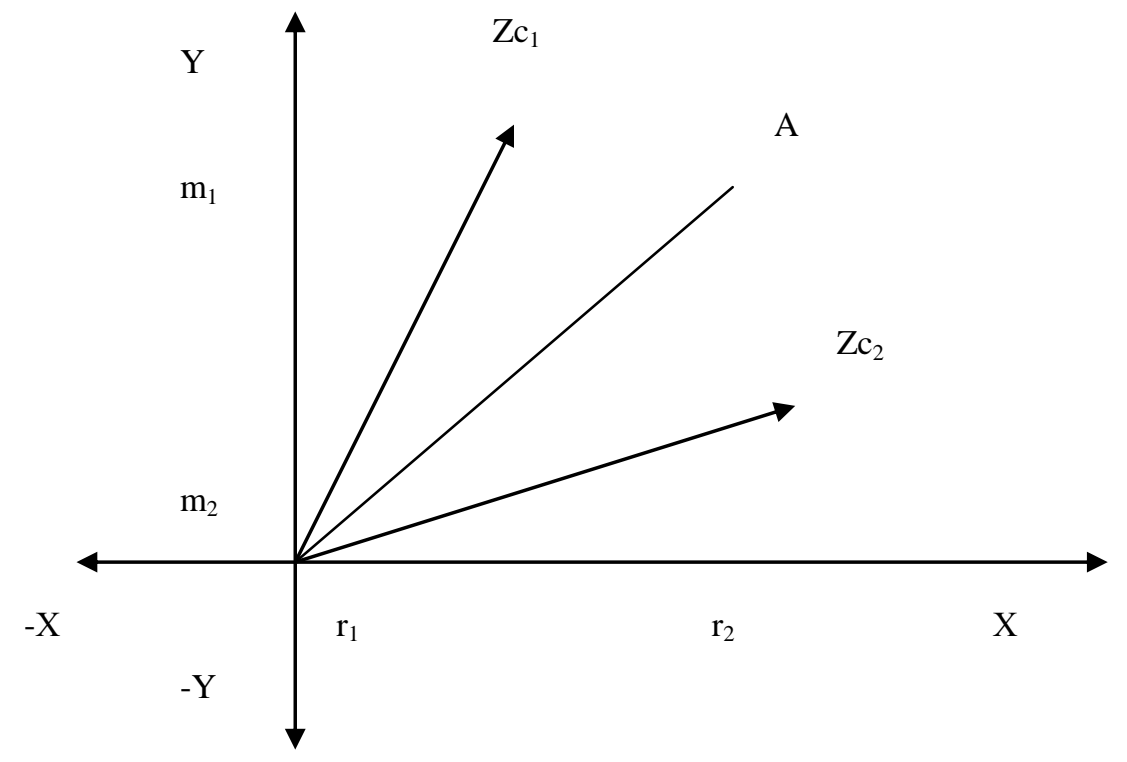

Based on a set of known (estimated) specific values of $r$ and $m$, we can judge about $\mathrm{Z}_{\mathrm{c}}$. We can check whether $\mathrm{Z}_{\mathrm{C}}$ is undervalued or overvalued comparing with its basis; hence estimate a size of the "bubble". Our analysis is based on the mathematical theory of complex numbers with the help of fundamental and technical analysis of trends in prices for securities. This indicator can simultaneously analyze the relationships in the fundamental value and the price of securities. According to the analysis, you can evaluate not only the quality of the security and the size of its "bubble", but also the effectiveness of policies of corporate and financial management of the company in general.

\section{Geometric interpretation of $Z_{C}$ indicator}

In the plain (Figure 2) $\mathrm{Z}_{\mathrm{C}}$ can be illustrated by coordinates of $(\mathrm{r}, \mathrm{m})$, where: $\mathrm{Y}$ - axis of imaginary numbers, which are the market price of shares of listed companies; $\mathrm{X}$ - axis of real numbers, which are the real value of the shares, calculated on the basis of fundamental analysis of the company. We assume that (in Figure 2) there are two resulting vectors $\mathrm{Z}_{\mathrm{C} 1}$ and $\mathrm{Z}_{\mathrm{C} 2}$ with coordinates of $\left(\mathrm{r}_{1}, \mathrm{~m}_{1}\right)$ and $\left(\mathrm{r}_{2}, \mathrm{~m}_{2}\right)$ respectively. The gap between the vectors and $0 \mathrm{~A}$ line is the same. $0 \mathrm{~A}$, in turn, has got a slope of 45 degrees. We can consider it as a bottom line of a "bubble". In particular the vector $\mathrm{Z}_{\mathrm{C} 1}$ is above the line $0 \mathrm{~A}$ (with a slope of 67,5 degrees), which means that the price with regards to $\mathrm{Y}$ has reached its critical limit of a "bubble", and consequently the critical value of investment risk. In comparison, the vector $\mathrm{Z}_{\mathrm{C} 2}$ (with a slope of 22, 5 degrees) does not include a "bubble".We can take the gap between $\mathrm{Z}_{\mathrm{C} 1}$ and $\mathrm{Z}_{\mathrm{C} 2}$ as the area of a just value in the geometric model (Figure $2)^{11}$. Moreover, the volume of the "bubble" depends on the expectation, the interests and behavior (including psychology, reflexivity) of investors and issuers in the market, and also the efficiency rate of market regulation and its equivalent relationship with the real economy. The actions (decisions) of investors and issuers occasionally do not coincide with the condition of a real basis. It brings to volatility of a security in the market.

There may be various cases on the direction of a vector, which estimates the complex indicator of a company's value. If the vector $\mathrm{Z}_{\mathrm{C}}$ is in a quartile $(\mathrm{X}, \mathrm{Y})$, and its slope is more than 67,5 degree, it means that a security has a high rate of liquidity, and that the speculative market is "overheated". In this case the investment risk is also very high, because the volume of a "bubble" overcomes the critical frontier. This is a warning signal for the investors, and a subject to strengthening the control and to making decisions on eliminating the risky "bubble" for the regulators. If the vector $\mathrm{Z}_{\mathrm{C}}$ is in a quartile $(-\mathrm{X}, \mathrm{Y})$, it means that a security is "overrated" unjustifiably. This is a signal of a bankruptcy of the company. Thus the investors try to eject the

\footnotetext{
${ }^{11}$ Similarly, in the 3D-model (Figure 1).
} 
securities to the market, because of high investment risk or sanitations. If the vector $\mathrm{Z}_{\mathrm{C}}$ is in a quartile (-X, $\left.-\mathrm{Y}\right)$, it means that the company (issuer) is in the state of a bankruptcy.

If the vector $Z_{C}$ is in a quartile $(X,-Y)$, it means that can serve as a signal for a venture capitalists (investors). If the vector $Z_{C}$ is in a quartile $(X, Y)$, and its slope is less than 22,5 degree, it means that a security has a low rate of liquidity, and even it is undervalued by the market, it has a potential to rise in price. This is a signal to act for the strategic and speculative portfolio investors. It appears that the investors tend to take a greater risk in business, when they deal with liquid assets, regardless of the presence of a "bubble". The higher the liquidity, the higher is the volume of the "bubble". Consequently in the geometric interpretation we can estimate the level of the investment risk in the plane X, Y (Figure 2) according to the angles with respect to the line $0 \mathrm{~A}$. The Figure 2 illustrates that the lengths of the vectors $\mathrm{Z}_{\mathrm{C} 1}$ and $\mathrm{Z}_{\mathrm{C} 2}$ are very significant in analysing a company's value. This statement becomes convincible if we add and/or deduct vectors with respect to the shares of a company in calculating the resulting vector $\mathrm{Z}_{\mathrm{C} 1}$ or $\mathrm{Z}_{\mathrm{C} 2}$ for a particular period of time. Eventually, we have the following picture (consistent pattern): the more the length of the vector the better is the quality of the security, if the vector is in the lowest risk (X, Y) quartile with the slope of less than 67, 5 degrees. The best quality securities are the ones that have the same $r$ and $m$ in a complex number coincidentally, or when $r \leq \mathrm{m}$.

\section{Conclusion}

The described representation of $\mathrm{Z}_{\mathrm{C}}$ (as a complex number) leads to more informative and complete results as it allows:

- to use methods of fundamental and technical analysis in complex;

- to analyse $\mathrm{Z}_{\mathrm{C}}$ in complex, particularly the cases based on the mathematical theory of complex numbers;

- participants (issuers, investors, intermediaries) of SM to make more confident decisions for the effective activity;

- regulatory institutions of SM to make more informed and effective regulatory decisions;

- Managers to make informed decisions on policies and corporate financial management.

- Analysis based on models (Figures 1 and 2) indicate that:

- the just value of the issued securities may be selected from the alternate pair of "fundamental value of their real basis (issuer) - an objective market price" in the fairness gap, but outside of the gap it would be appropriate to use only a fundamental value;

- the just value of securities, therefore, the just value of the company should be represented as a function that has two interrelated and equivalent depended variables-a real (fundamental) value and an objective price (virtual value, quotes, etc.) of the securities. The objective market price of the securities in SM and the fundamental value of the company are formed on the basis of the principle of equivalence in the gap of justice (fairness).

The method is implemented by the following three-step generalized algorithm: Firstly, it is necessary to calculate the fundamental value, which is determined by the AM, is based on well-known assessment and economic analysis approaches and methods for assessing the value of a property. The second step is determining objective prices, which are formed on the property markets (i.e. SM).In the final step we identify the interrelation of price and value of a property by the geometric model, and eventually, a just value. In this case the just value is inside the segment of fair vectors, which are in the (X, Y) quartile. The segment boundaries are vectors with slopes of 22, 5 and 67, 5 degrees. In general, this geometric model is effective to be used in countries where pricing and value-creational markets are developed and integrated well enough.

\section{References}

Kudina M. V. (2010). Forming Company's Value: Theoretical and Methodological Aspects. Moscow: MoscowStateUniversity.

ShokhazamiySh.Sh. (2009). Macroeconomic Conditions and Potential of Anti-Crisis Activities - the MajorPremises of Strategic Development of Stock Market in Uzbekistan. BirjaEkspert, 7-8, 50-57.

ShokhazamiySh.Sh. (2010a). Economic Systemology: Concept and Implementation. Tashkent: Iqtisod-moliya. 
ShokhazamiySh.Sh. (2010b). How to Measure a "Bubble" in Stock Market. BirjaEkspert, 1, 35-38.

ShokhazamiySh.Sh. (2012a). Corporate Policy. Tashkent: Fan vaTexnologiya.

ShokhazamiySh.Sh. (2012b). Theory, Value and Price of Property. Tashkent: Fan vaTexnologiya.

ShokhazamiySh.Sh. (2012c). Systematic Development of Stock Market in Regulation Interrelation with Real Economy. Tashkent: Fan vaTexnologiya.

ShokhazamiySh.Sh. (2013a). Financialmetrics: Theoretical Foundations and Implementation. Tashkent: Iqtisod-moliya.

ShokhazamiySh.Sh. (2013b). Analysis of Equivalence and Distinction of Value and Price of Securities. Journal of Central Asian Economies, 4(1), 79-102. 